\title{
Video capsule endoscopy in familial adenomatous polyposis: capsule entrapment in an anal stenosis
}

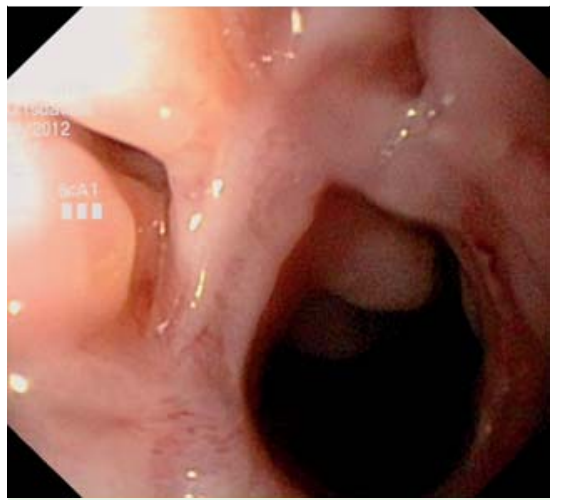

Fig. 1 A 44-year-old woman, who had undergone proctocolectomy with ileoanal pouch anastomosis 13 years earlier to treat colon carcinoma, underwent endoscopy, which showed stenosis of the ileoanal anastomosis 1 day before video capsule endoscopy (VCE).

A 44-year-old woman with familial adenomatous polyposis syndrome underwent video capsule endoscopy (VCE) (Pillcam SB2, 11.0 mm diameter; Given, Yoqneam, Israel) for suspected small-bowel adenomas. She had undergone proctocolectomy with ileoanal pouch anastomosis 13 years earlier to treat colon carcinoma. During the day of the VCE exam, endoscopy of the ileoanal pouch was performed showing a stenosis of the anal canal
(ه Fig. 1). Symptoms of this stricture had not been reported by the patient. A digital rectal exam was impossible as a result of the stenosis; however, the stricture could be passed with an endoscope of $9.8 \mathrm{~mm}$ diameter (Olympus GIF-H180). The pouch and neoterminal ileum showed no further abnormalities. Approximately 36 hours after administration of the video capsule, the patient developed abdominal pain. An abdominal computed tomography (CT) scan showed mechanical bowel obstruction as a result of capsule entrapment in the anal stenosis ( $\mathbf{F i g . 2 a , b}$ ). In a subsequent lower endoscopy, the retained capsule was recovered with a net retriever ( $\mathbf{F i g . 3}$ ), and the patient's obstructive symptoms resolved after the capsule's salvage. At 16-month follow-up, the patient remained asymptomatic from the anal stenosis.

VCE examination of the small bowel is indicated in patients with familial adenomatous polyposis with duodenal polyps [1]. The rate of capsule retention during VCE varies in the literature with a mean retention rate of $1.4 \%$ [2]. However, this event rarely leads to symptoms of bowel obstruction [2,3]. To the best of our knowledge, obstruction owing to capsule entrapment in an anal stenosis has not

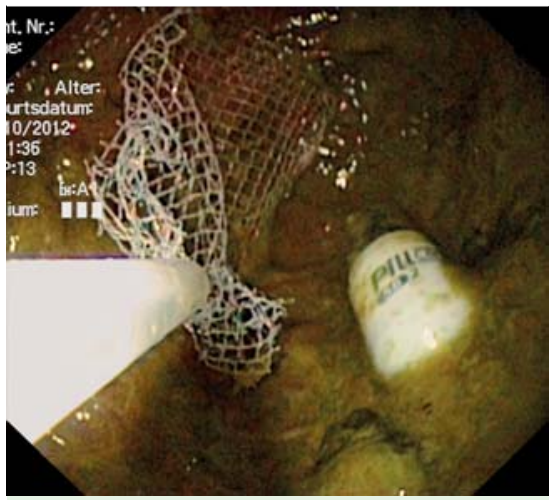

Fig.3 In a subsequent lower endoscopy, the impacted video capsule was recovered from the ileoanal pouch using a net retriever.

been reported. Furthermore, the retention could not have been anticipated in the light of the endoscopic passage of the anal stenosis on the same day as the capsule application [4]. Since VCE is recommended in patients with familial adenomatous polyposis to screen for smallbowel adenomas [5], capsule entrapment by anal stenosis, which is common after ileoanal pouch operation, needs to be considered in this patient group.

Endoscopy_UCTN_Code_CPL_1AI_2AB

Competing interests: None

\section{Franziska Durchschein, Florian Schreiber, Christoph Högenauer}

Department of Internal Medicine, Division of Gastroenterology and Hepatology, Medical University of Graz, Graz, Austria

\section{References}

1 Ladas SD, Triantafyllou K, Spada C et al. European Society of Gastrointestinal Endoscopy (ESGE): recommendations (2009) on clinical use of video capsule endoscopy to investigate small-bowel, esophageal and colonic diseases. Endoscopy 2010; 42: 220-227

2 Liao Z, Gao R, Xu C et al. Indications and detection, completion, and retention rates of small-bowel capsule endoscopy: a systematic review. Gastrointest Endosc 2010; 71: $280-286$

3 Karagiannis S, Faiss S, Mavrogiannis C. Capsule retention: a feared complication of wireless capsule endoscopy. Scand J Gastroenterol 2009; 44: $1158-1165$ 
4 Leighton JA, Legnani P, Seidman EG. Role of capsule endoscopy in inflammatory bowel disease: where we are and where we are going. Inflamm Bowel Dis 2007; 13: 331 337

5 Iaquinto G, Fornasarig M, Quaia M et al. Capsule endoscopy is useful and safe for smallbowel surveillance in familial adenomatous polyposis. Gastrointest Endosc 2008; 67: 61-67

\section{Bibliography}

Dol http://dx.doi.org/

10.1055/s-0034-1377640

Endoscopy 2014; 46: E529-E530

(c) Georg Thieme Verlag KG

Stuttgart · New York

ISSN 0013-726X

\section{Corresponding author}

\section{Franziska Durchschein, MD}

Department of Internal Medicine

Division of Gastroenterology and Hepatology

Medical University of Graz

Auenbruggerplatz 15

A-8036 Graz

Austria

Fax: +43-316-3852648

franziska.durchschein@medunigraz.at 